\title{
Assessment in Teacher Education: North \& South [ATENS]
}

\author{
By Geraldine Magennis * \\ Tracey Connolly ${ }^{\prime}$
}

\begin{abstract}
Central to successful learning and teaching is assessment. Therefore, this small-scale, Irish, cross-border research project investigates the assessment of and satisfaction with school-based placements as experienced by a sample of primary and post-primary students and their college tutors. The resultant connections between such professional practices and subsequent planning, teaching and learning are also examined. Reflective of current practices in formative modes of assessment and being particularly relevant to the experience of pre-service teachers, Rogoff's (1995) socio-cultural theory has been chosen to underpin this project. It explores the balance between personal, interpersonal and cultural factors in learning as student teachers journey toward newly-qualified status. Due to the 'lived' nature of this research project, an interpretative approach is taken in the form of descriptive, thematic analysis. The project illuminates the reduced time and space students have to explore, integrate and reflect upon theory-pedagogy links and to conduct professional, collegial conversations. Completing extraneous and repetitive college paperwork, often excluded many from their schools' communities of practice. Current assessment methods are deemed subjective and somewhat non-representative of teaching practice placement especially in terms of relationships forged and learning completed. A disconnect exists between the reality of practice within individual, engrained school cultures and procedures and college provision. Despite both tutors and students largely endorsing assessment for learning as a journey, students tended to formalize the process to achieve high grades. Sadly, few if any linkages were made between the students' own experiences of being assessed and their subsequent planning, teaching and assessment of their pupils. ${ }^{l}$
\end{abstract}

\footnotetext{
${ }^{*}$ Senior Lecturer, St Mary's University College, Northern Ireland.

'Lecturer, University College, Cork, Republic of Ireland.

${ }^{1}$ Acknowledgement is due to Dr Alicia Curtin, research assistant on the original research project.
} 


\section{Rationale}

The concept of assessment has received much attention in educational literature (e.g., Black \& Wiliam, 1998a, 1998b \& 1999; Gardner, 2006) because it is now seen as an equally important element in the teaching and learning cycle. Huba and Freed (2000) broadly define it as the process of gathering and discussing information from multiple and diverse sources in order to develop a deep and vivid picture of students' knowledge and understanding. Such a process then allows for the provision of feedback to learners so that they are aware of how to help progress their own learning. Thus, both Assessment of Learning (summative) and Assessment for Learning (formative) have been explored and critiqued for use in classrooms across all age ranges (e.g., Assessment Reform Group, 2002; Gardner et al., 2010). Indeed, the assessment landscape has been further defined in recent years with the inclusion of Assessment as Learning (Bloxham, 2008). Subsequently, the ensuing educational debates and resultant curricular innovations in Northern Ireland (Council for Curriculum \& Assessment [CCEA], 2007) and the Republic of Ireland (National Council for Curriculum \& Assessment [NCCA], 2007) have served to secure the important place and role of assessment in the business of teaching in general.

This renewed emphasis on the need for professional reflection as embodied in formative assessment practices in particular is supported by the Organisation for Economic Cooperation and Development (OECD) report (2005a) entitled 'Teachers Matter'. Akin to this, is the Teaching Council's Policy on the Continuum of Teacher Education (2011) which queries the limited time and space given over to the meaningful cultivation of beginning teachers as reflective, enquiry orientated, lifelong learners. It emphasises the necessity of developing student teachers as continuous self evaluaters and collaboraters in order to ensure that they can adapt throughout their careers and in addition keep the profession fresh. Indeed, this philosophy underpins the current changes being implemented in teacher education courses in the Republic of Ireland as well as the existence of the General Teaching Council of Northern Ireland's (GTCNI, 2007) competency based reflective pratitioner model.

Set against the above context, this study is timely since those going out to teach will be expected to assess their pupils with competence and confidence. Therefore, it is imperative that they have a deep understanding and experience of having been meaningfully assessed themselves. In that way it is more likely that they will be better equipped to provide the same quality service for others. This is all the more important since teachers will be educating pupils to take their place in the wider world of work which places increasing demands on employees to engage with various modes of communication, technology and self development programmes. Therefore, being able to know oneself as a learner and having a bank of resources to draw on in order to further develop one's own knowledge base and skill set is essential. However, in the professional experience of both authors, it was often noted that students tended 
to return to the default position of awaiting assessment to 'be done onto them' by their tutors whilst on teaching practice rather than expecting to be an integral part of the decision-making process. This prompted us to consider how such a retrograde step in students' thinking might impinge on their ability to assess their own pupils might be affected. Consequently, our overall research questions revolved around not only what was being assessed on School Based Work placements in Initial Teacher Education but how was this being done, where was the place of the student teacher as co-assessor and how did their own assessment experiences influence their ability to assess their pupils?

A thorough examination of the literature is now a necessary segway into the findings and subsequent discussions of this research project.

\section{Literature Review}

There is an old proverb that says 'One man's meat is another man's poison'. This refers to the subjective nature between individuals' tastes and opinions on any given matter. Such a philosophy holds true across a multitude of subjects and situations, including what constitutes best practice in education. This being the case, the thorny issue of how we measure or judge 'good' teaching and learning experiences presents itself. In attempting to solve such a conundrum, the Teaching Council of Ireland (2012) lists nine characteristics of effective school placement, namely:

1. a strong focus on learning,

2. relationships built on the core values of respect, trust and inclusion,

3. partnership,

4. professional engagement and ownership,

5. a whole school approach,

6. innovation,

7. integration,

8. improvement,

9. relationships and communication.

These tenets also closely mirror the reflective practitioner model (GTCNI, 2007) that underpins initial teacher education preparation courses in the north of Ireland. These philosophies are dominated by characteristics relating to the formation of knowledgeable, thinking, creative, collaborative practitioners who actively participate in the betterment of their own and others' holistic life experiences.

Embedded within these philosophies is the concept of assessment. In recent years it has acquired a new-found status in the conduct of both educational research and classroom practice. Generally, debates lie around the summative versus formative polemic, often resulting in the jaundiced insinuation that they are mutually exclusive. Gardner et al. (2010) make the 
crucial point that assessment activity itself is not inherently formative or summative but rather that it is the use to which it is put that defines it as such. If testing is used to improve pupil learning, it is formative (assessment for learning) but if the same testing is used to provide a result that will feature in a report, it is summative, (assessment of learning). Although this study touches on this dilemma, its focus centres mostly on the contradictory impacts current assessment procedures have on the dynamics of becoming and/or helping shape the formation of pre-service teachers. By blending socio-cultural and assessment theories, this study seeks to help cultivate an educational/cultural mindset around meaningful encounters of partnership between learner and educator. To this end, the Analysis and Review of Innovations in Assessment's 'Principles of Assessment Practice' (Gardner et al., 2010:106-107) were chosen as a guideline to determine our exploration of trainee teachers' experiences of assessment in their teaching placements.

\section{Principles of Assessment Practice}

Assessment should:

1. ultimately improve learning

2. enable progress in all important learning goals to be facilitated and reported

3. include explicit processes to ensure that information is valid and is as reliable as necessary for its purpose

4. promote public understanding of learning goals relevant to students' current and future lives.

5. [Assessment of learning outcomes should] be treated as approximations and subject to errors.

6. be a part of a process of teaching that enables students to understand the aims of their learning and how the quality of their achievement will be judged.

7. promote the active engagement of students in their learning and its assessment.

8. enable and motivate students to show what they can do.

9. combine information of different kinds, including students' selfassessments, to inform decisions about students' learning and achievements.

10. meet standards that reflect a broad consensus on quality at all levels from classroom practice to national policy.

In essence, such principles advocate that assessment should be a relevant, transparent, multi-faceted and organic process that ultimately improves learning.

In 1998(b) Black and Wiliam's seminal article 'Inside the Black Box: Raising Standards Through Classroom Assessment', identified the potentially sizable benefits to be made in learning when formative assessment is used as evidence to adapt teaching to meet students' needs. Such sentiments were 
corroborated in the OECD's 2005(b) report that describes formative assessment as 'perhaps one of the most important interventions for promoting high performance ever studied (p22)'. Unsurprisingly therefore, much contemporary research has been attempting to connect college and school experience as a result (Grossman et al., 2009: Zeichner, 2009). Consequently, practices such as observation, reflection, mentoring and peer learning are woven into teacher education courses to varying degrees and in various forms. Despite this, understanding and implementation of formative assessment in teacher education programmes nationally and internationally has proven to be a complex and challenging endeavour.

The misunderstanding and misuse of formative assessment is due in part to what Black and Wiliam (1998b) term as a poverty of practice in schools alongside an empty commitment from policymakers and institutions. In their follow-up article 'Assessment for Learning: Beyond the Black Box' (1999), they outline five deceptively simple factors that help improve assessment and in turn learning. These are:

1. the provision of effective feedback,

2. the active involvement of pupils in their own learning,

3. adjusting teaching to take into account the results of assessment,

4. a recognition of the profound influence assessment has on the motivation and self esteem of pupils and

5. the need for pupils to be able to assess themselves and understand how to improve.

These factors echo Gardner et al's (2010) understanding of assessment, namely that it occurs most effectively in a rich, mutually repectful and participatory atmosphere. In other words, it is a socially dependent and by extension culturally defined endeavour.

\section{Rogoff's Socio-Cultural Theory}

Barbara Rogoff's (1995) socio-cultural theory is deemed particularly relevant to the experience of student teachers since it readdresses the balance between personal, interpersonal and cultural factors in learning. She claims that individuals and their environment and actions are inextricably linked, thus all such elements of an encounter or endeavour bring context and intelligibility to a situation. Therefore, she moves assessment from the sole responsibility of the educator to the shared responsibility of the educator and learner, taking into account the supporting landscape of experience, language, histories etc. She conceives of participation in communities as occurring across three interlinked and interdependent planes that are multi-layered and non-hierarchical sites where learning occurs simultaneously since all three planes are 'mutually constituting' (Rogoff, 1995:139). It is perhaps helpful to think of these planes as spheres of experience rather than concrete places such as college, school etc. 
Members often hold varying status in participation, depending on whichever community of practice they find themselves in.

The metaphor of 'apprenticeship' refers to participation relating to community, culture and family around shared funds of knowledge (Gonzalez, Moll \& Amanti, 2005). Members of such communities of practice increase their expansive skills and understanding through active participation with others in 'culturally organised' activities (Rogoff, 1995:142). It acknowledges that the specific goals of the community are shaped by the 'institutional structure and cultural technologies of intellectual activity' (Rogoff, 1995:143146). In other words, cultural constraints, values, resources and tools define and influence that particular community and its activities. Therefore, student teachers cannot be a homogeneous group since they enter teaching practice shaped by their own unique histories, relationships, learning and assessment experiences which in turn shape their practice and identity formation.

'Guided participation', refers to the social or interpersonal experiences concerned when in the novice phase of learning. It alludes to such activities as conversations, communications, interactions and collaboration which occur between individuals as they negotiate and co-ordinate their participation in 'socio-culturally structured collective activity' (Rogoff, 1995:146). It includes both deliberate attempts to instruct and casual conversations that occur between expert and learner or among learners. For student teachers, this plane identifies their need to be allowed and indeed facilitated to learn from interactions with and relationships between each other, colleagues, supervisors and mentors.

The basic idea of the final plane, 'participatory appropriation' is that through social participation, individuals transform their understandings of and engagement in similar future activities. This personal plane of learning includes many aspects such as cognition, emotion, behaviour, values and beliefs. Consequently, this study examines the extent to which student teachers are given the freedom to reconcile the college demands of teaching practice and the schools' expectations as they journey toward their own understanding and practice of what it means to be an educator. In other words, from the point of view of agency, how do trainee teachers perceive their role[s] as they move within and between these interlinking communities of practice?

\section{Data Collection \& Analysis}

Thirteen courses drawn from seven colleges across the island of Ireland were our selected sample. They included both primary and post primary pathways within undergraduate and postgraduate courses. Focus group interviews were held with 6-8 students from each of the courses chosen. In the case of B Ed courses, final year students were earmarked while in the one year post-graduate certificate courses, interviews were held after students' final placements, where feasible. It was expected that having been through the maximum number of placements they would have the most to contribute to the project in terms of experience. In addition, individual interviews were carried 
out with School Placement Coordinators and teaching practice tutors in each institution. Both sets of interviews were semi-structured, audio-recorded and transcribed for the final analysis. To support our understanding of the specifics of teaching practice and therefore the design of our data collection instruments, we completed a document comparison of student handbooks, course guides and related School Based Work paperwork ahead of meeting the sample.

In order to best capture the lived experiences of the student teachers our study necessitated a qualitative approach represented by the use of narrative and rich, shared discussion. From these conversations it was possible to then identify emerging themes. These are then analysed in the light of Rogoff's (1995) socio-cultural planes of participation theory and formative assessment literature. As a result, practical recommendations are offered as an invitation to teacher educators to consider other possible approaches to assessing teaching placement that might enhance their current practice.

\section{Results \& Discussion}

In the 'apprenticeship' phase where the beginnings of mature participation in such 'culturally organised' (Rogoff, 1995:142) activities as planning occurs, there appears to be disparity between what tutors expect and are seen to value in regards to paperwork and what students understand the paperwork to entail, especially in terms of priority status. This is exacerbated by two things, namely the tutors' perceived preferences and personality traits. When their apprenticeship moves out into schools, clashes sometimes occur where additional and sometimes different cultural practices and priorities exist.

The apparent perception is that paperwork tasks are to be ticked off students' to-do lists in a product driven manner, largely because of the quantity of content to be covered. Conversely, tutor feedback on the teaching practice file favours a checklist-type of system and this seems to reinforce the tendency to lean toward summative rather than formative [or a mixture of] assessment practices and purposes. In addition, professional discussions, peer review and debriefing from observations become diminished in essence. Where they do exist, they tend to serve pragmatic purposes rather than the deepening and development of pedagogical practice. Ironically, many of the students display very positive attitudes toward assessment and recognize the value and potential for professional growth inherent in formative methods if harnessed and focused in a particular way. Unfortunately, what appears to be a process to be engaged in deeply, conversed about with peers and elders over time is being turned into a subjective product to be graded and therefore, for the most part remains apart from students' vibrant, lived experiences.

Learning through 'guided participation' is extremely important for student teachers since it facilitates them moving from legitimate peripheral participation where they watch and learn from colleagues to becoming fully functioning members of the host school. Despite overall acknowledgement of 
the value and necessity of mentorship by the mentor teachers, it appears to be a loosely defined concept. Consequently, it would seem that no particular perimeters are negotiated and so great variance in experience occurs. There is a widespread feeling among students that much of their success [or failure] depends on the personal and professional relationship engendered between them and their host teachers. Many mentor teachers are reluctant to stipulate the nature and conduct of this relationship due to uncertainty about their precise roles. Tutors endorse the value of having the host teachers' input but again exactly how this manifests remains nebulous.

Similarly, confusion and ambiguity abound in terms of the role of the college tutor. Again, students admit to aiming to please perceived personality types in order to gain a high grade. More concerning is that they believe that they may be penalized due to the subjective nature of assessment and the chasm that can sometimes exist between conflicting tutors' opinions. Grade descriptors were found by many to be ambiguous and difficult to align with tutors' written feedback, thus stifling their ability to put into practice advice given. Peer-teaching and learning varied substantially despite being generally hailed as beneficial across all sites. Most pointedly, students really craved peer and tutor dialogue in order to process this very important phase of their developing practice. Tutors acknowledged the value of such collaborations and interactions. Self-assessment was less enthusiastically embraced and when it became a requirement to report on such reflections as part of summative assessment, students tended to treat their lived experiences as products to be graded.

During 'participatory appropriation', trainee teachers are recognised as having reached a level of professional maturity whereby they are now ready to be initiated formally into the teaching fraternity. Some were openly welcomed into their chosen communities of practice and perceived as fresh, 'new blood' while others were viewed more as outsiders or perhaps threats. Unsurprisingly, when students felt respected and appreciated their willingness to assist both in and outside of school hours increased. They relished fuller involvement in all aspects of school life and indeed felt that this enabled them to show their true capabilities.

It would appear from the conclusions drawn across all phases of participation, that the ideals of having a strong focus on learning (1) and the need for partnership (3) as outlined in the Teaching Council of Ireland's (2012) list of effective school placement indicators are largely absent. There is a sharp sense of mechanical immediacy as opposed to rich and knowledgeable understandings of how the complex nature of teaching, learning and assessment might be represented on paper. Likewise, professional engagement and ownership (4) is very much conspicuous by its absence in the somewhat unilateral exchanges unearthed in this study. Needless to say, the possibility of improvement (8) for the students is diminished as they aim to please perceived personality types and their respective agendas. Perhaps most worryingly is the fact that the relationships and communication (9) between colleges and schools as well as between the students, tutors and host teachers is relatively fractured. 
Apart from the fact that each individual and each group of interviewees possess varying viewpoints on the nature and conduct of teaching, learning and assessment, there appears to be a deferential approach to the colleges as being the arbiter of what constitutes success [or failure] in the field of student placement. Surely this does not echo the values of trust, respect, fairness and equality for all as outlined explicitly in the GTCNI's (2007) teacher competencies.

Moreover, these dynamics speak of the real conflicts of purpose around assessment that exist as outlined by Bloxham (2008), depending on the particular stakeholders' priorities. Although the theory around current assessment favours the betterment of student and lifelong learning, the practice appears to lean toward the securing of certification, quality assurance, accountability and selection. These tensions and contradictions within assessment in higher education are even more starkly juxtaposed when compared to assessment in other craft apprenticeships where features such as goal transparency, modeling, authentic usage, collegial and end user feedback and self responsibility with a view to progression prevail (Kvale, 2007).

Specifically, many of the above findings contravene the Principles of Assessment Practice (Gardner et al., 2010), particularly in relation to the first tenet that states it 'should ultimately improve learning'. In fact, there is little evidence that any of the principles are being met meaningfully since they advocate active, participatory, flexible and collaborative experiences. They speak of the presence of uncertainty within the judgments made with a view to negotiation and change never being far away. This view is corroborated by the complete lack of material in the final analysis relating to how students assess their own pupils and the impact (or lack thereof) that their own experiences have had on this. This was despite the fact that it pertains directly to our research questions and therefore featured explicitly in data gathering discussions. Although it is not possible to discern how well students have been able to assess their own pupils, the fact that such a connection was repeatedly overlooked as warranting emphases by interviewees is surely somewhat alarming.

This resonates with Black and Wiliam's (1998b) initial claim that engaging in effective formative assessment is deceivingly difficult because it looks easy on paper. This could lead us to conclude that on the courses surveyed; the connection between being assessed as students formatively or summatively and assessing pupils out in schools is weak and requires much more clarity and articulation. A similar call has been made by a team of researchers at Queen's University in Belfast who have just completed a follow up study where they consulted pupils on assessment of their learning (Leitch et. al, 2008: Leitch et. al, 2013 forthcoming). Both studies show the complex nature of assessment and the considerable room for miscommunication that exists between educator and learner.

Again, this disconnect seems to be due in part to the cloudiness around whether student teachers are participating in a learning process or acquiring a 
product they will have to market later on. Understandably in this present economic recession, there is a strong sense among students that a high teaching practice grade will privilege them in gaining employment. Therefore, the product rather than the process is the Holy Grail. The rhetoric of current curriculum change and assessment theory is that of a socially and culturally embedded journey while the reality of implementation is one of a relatively disembodied experience that leads to a definite, graded destination. Perhaps few practitioners really know the language or have engaged in the necessary conversations around these concepts as they hone their own practices. If this is the case, then it is not surprising that student teachers are naturally unaware of these concepts or indeed do not know the language or how to become involved or be invited into such professional circles (Lave \& Wenger, 1991). In roads into changing this situation might begin with Bloxham and Boyd's (2007: 225) advice whereby they encourage 'a critical and scholarly interrogation of assessment practice' hopefully leading to 'a balance between expansive and restrictive learning environments'. Only in this way will there be any chance of increasing student teachers' and by extension their pupils' 'learning processes and products' (Hargreaves, 2005:213).

Throughout this paper, it is hoped that the complex and contradictory nature and conduct of teaching, learning and assessment has been demonstrated. In endeavouring to critique and improve current practice, the following far reaching ideas are suggested.

1. The explicit interrogation of what assessment means and what its goals are in each institution.

Discussing and sharing the various understandings of the multifaceted nature of assessment held by the myriad of stakeholders across all sites of is required. These definitions then need to be addressed within the wider educational contexts [national policy, curriculum demands, school level, age phase etc.] so as to identify the tensions that exist between the respective components. Perhaps staff development programmes within and across schools and colleges would provide fruitful opportunities for these kinds of conversations to occur as necessary prerequisites of policymaking around procedures.

2. The facilitation of deeper, more genuine and creative partnerships between college staff, students and schools' personnel.

Explicit role redefinement for all participants but most especially students, needs to happen so that discrepancies become diminished. Boud and Falchikov (2007) note that in order to promote students' informed judgments they must first see themselves as active learners. Exploration of the concept of active learner and how this might manifest in preparation for, during and after school placement is essential. Boud and Falchikov (2007) caution the need for staged examination and development of expertise on behalf of and with the learners. 
Perhaps further consultation with the student body on how their roles might be developed to entail fuller, active engagement in their own learning and assessment would be a good starting point. They may have some 'insider' suggestions on the kinds of assessment techniques that lend themselves to allowing students to contribute concretely to their professional development.

It might also be feasible to begin negotiations around mentors having a greater and more influential role as formal co-assessors of their students. After all, they are steeped in the culture and practices of teaching, learning and assessment and so are vital resources.

Transparency and consistency among tutors, in terms of what is being assessed and how it is being assessed is urgently required. Space and time to explore their individual and collective understandings of what it means to meaningfully assess the socially and culturally defined nature of teaching and learning and how this might best be done is required. Clear communication around tutor debriefing sessions is lacking since some of the intended impact gets lost in translation.

Although these recommendations appear easy, they do require considerable time and commitment if they are to help move all stakeholders toward a more synergetic relationship which will ultimately bear fruit for pupils. By shifting the cultural/educational mindset to one that is more representative of expansive learning, it is hoped that that most essential connection between the student teachers' own positive experiences of assessment will be used to the full in classrooms across the island of Ireland. Only then will the paperwork involved hold more meaning and power for everyone.

\section{Bibliography}

Assessment Reform Group (1999) Assessment for Learning: Beyond the Black Box. Cambridge: University of Cambridge.

Black, P. \& Wiliam, D. (1998a) Assessment \& Classroom Learning. Assessment in Education Volume 5 (1) pp.7-71

Black, P. and Wiliam, D. (1998b) Inside the Black Box: Raising Standards Through Classroom Assessment. Phi Delta Kappan, Volume 80 (2) 139-148

Black, P. \& Wiliam, D. (1999) Assessment for Learning: Beyond the Black Box. Cambridge: University of Cambridge School of Education.

Bloxham, S. (2008) Assessment in Teacher Education Stakeholder Conflict \& It's Resolution. Practitioner Research in Higher Education Volume 2 (1) pp.13-21

Bloxham, S. \& Boyd, P. (2007) Developing Effective Assessment in Higher Education: A Practical Guide. Berkshire: Open University Press.

Gardner, J., Harlen, W., Hayward, L. \& Stobart, G. with Montgomery, M. (2010) Developing Teacher Assessment. London: McGraw Hill

Gardner, J. [ed] (2006) Assessment \& Learning. London: Sage.

General Teaching Council of Northern Ireland (GTCNI) (2007) Teaching: The Reflective Profession. Belfast: GTCNI http://www.gtcni.org.uk/ 
Gonzalez, N., Moll, L.C., \& Amanti, C. (2005) Funds of Knowledge: Theorizing Practices in Households and Classrooms. Lawrence Erlbaum Associates

Grossman, P., Compton, C., Igra, D., Ronfeldt, M., Shahan, E. \& Williamson, P. (2009) Teaching Practice: A Cross-Professional Perspective. Teachers College Record Volume 111 (9), September 2009, pp. 2055-2100

Hargreaves, E. (2005) Assessment for Learning? Thinking Outside the (Black) Box. Cambridge Journal of Education, Volume 35 (2), pp.213-224

Huba, M. E. \& Freed, J. E. (2000) Learner-centered Assessment on College Campuses: Shifting the Focus from Teaching to Learning. Boston, MA: Allyn \& Bacon.

Kvale, S. (2007) Contradictions of Assessment for Learning in Institutions of Higher Learning in Boud, D. \& Falchikov, N. [Eds] (2007) Rethinking Assessment in Higher Education: Learning for the Longer Term. London: Routledge.

Lave, J. \& Wenger, E. (1991) Situated Learning: Legitimate Peripheral Participation. Cambridge: University of Cambridge Press

Leitch, R., Gardner, J., Lundy, L., Clough, P., Odena, O., Mitchell, S. \& Galanouli, D. (2008) Consulting Pupils on the Assessment of Their Learning. Teaching \& Learning Research Briefing. Belfast: School of Education, Queen's University. March 2008, Volume 36, pp.1-4 http://www.tlrp.org/pub/documents/Leitch\% 20RB\%2036\%20FINAL.pdf

Leitch, R., Gardner, J. \& Mitchell, S. (2013 forthcoming) Consulting Pupils on the Assessment of Their Learning (CPAL2). Belfast: School of Education, Queen's University. http://www.cpal2.org

National Council for Curriculum \& Assessment (2007) Assessment in the Primary School Curriculum, Guidelines for Schools. Dublin: NCCA

Office for Economic Co-operation \& Development (OECD) (2005a) Teachers Matter: Attracting Developing \& Retaining Effective Teachers. France: OECD Publishing

Office for Economic Co-operation \& Development (OECD) (2005b) Formative Assessment: Improving Learning in Secondary Classrooms. France: OECD Publishing

Rogoff, B. (1995) Observing Socio-cultural Activity on Three Planes: Participatory Appropriation, Guided Participation, and Apprenticeship. In J.V. Wertsch, P. del Rio, \& A. Alvarez (Eds.), Sociocultural Studies of Mind (pp. 139-164). Cambridge: Cambridge University Press.

Teaching Council of Ireland (2012) Draft Guidelines on School Placement. http://www.teachingcouncil.ie/

Teaching Council of Ireland (2011) Policy on the Continuum of Teacher Education. Maynooth: Teaching Council of Ireland. http://www.teachingcouncil.ie/_ fileupload/Teacher\%20Education/FINAL\%20TC_Policy_PaperSP.pdf

Zeichner, K. (2010) Rethinking the Connections Between Campus Courses \& Field Experiences in College- \& University-Based Teacher Education. Journal of Teacher Education, Volume 61, (1-2), pp.89-99. USA: SAGE Publications http://www.ctc.ca.gov/educator-prep/TAP/Zeichner.pdf 